\title{
The effects of constructing domain-specific representations on coordination processes and learning in a CSCL-environment
}

Citation for published version (APA):

Slof, B., Erkens, G., \& Kirschner, P. A. (2012). The effects of constructing domain-specific representations on coordination processes and learning in a CSCL-environment. Computers in Human Behavior, 28(4), 1478-1489. https://doi.org/10.1016/j.chb.2012.03.011

DOI:

10.1016/j.chb.2012.03.011

Document status and date:

Published: 01/07/2012

Document Version:

Peer reviewed version

Please check the document version of this publication:

- A submitted manuscript is the version of the article upon submission and before peer-review. There can be important differences between the submitted version and the official published version of record. People interested in the research are advised to contact the author for the final version of the publication, or visit the DOI to the publisher's website.

- The final author version and the galley proof are versions of the publication after peer review.

- The final published version features the final layout of the paper including the volume, issue and page numbers.

Link to publication

\section{General rights}

Copyright and moral rights for the publications made accessible in the public portal are retained by the authors and/or other copyright owners and it is a condition of accessing publications that users recognise and abide by the legal requirements associated with these rights.

- Users may download and print one copy of any publication from the public portal for the purpose of private study or research.

- You may not further distribute the material or use it for any profit-making activity or commercial gain

- You may freely distribute the URL identifying the publication in the public portal.

If the publication is distributed under the terms of Article $25 \mathrm{fa}$ of the Dutch Copyright Act, indicated by the "Taverne" license above, please follow below link for the End User Agreement:

https://www.ou.nl/taverne-agreement

Take down policy

If you believe that this document breaches copyright please contact us at:

pure-support@ou.nl

providing details and we will investigate your claim.

Downloaded from https://research.ou.nl/ on date: 26 Apr. 2023 


\title{
The effects of constructing domain-specific representations on coordination processes and learning in a CSCL-environment
}

\author{
Bert Slof $^{\mathrm{a}, *}$, Gijsbert Erkens $^{\mathrm{b}}$, Paul A. Kirschner ${ }^{\mathrm{c}}$ \\ ${ }^{a}$ University of Groningen, P.O. Box 800, 9700 AV Groningen, The Netherlands \\ ${ }^{\mathrm{b}}$ Utrecht University, P.O. Box 80.140, 3508 TC Utrecht, The Netherlands \\ ' Open University of the Netherlands, P.O. Box 2960, 6401 DL Heerlen, The Netherlands
}

\section{A R T I C L E I N F O}

\section{Article history:}

Available online 20 April 2012

\section{Keywords:}

Complex learning-tasks

Coordination processes

Computer supported collaborative learning

External representations

Representational scripting

\begin{abstract}
A B S T R A C T
This study examined the effects of scripting learners' use of two types of representational tools (i.e., causal and simulation) on their online collaborative problem-solving. Scripting sequenced the phase-related part-task demands and made them explicit. This entailed (1) defining the problem and proposing multiple solutions (i.e., problem-solution) and (2) evaluating solutions and coming to a definitive solution (i.e., solution-evaluation). The causal tool was hypothesized to be best suited for problem solution and the simulation tool for solution evaluation. Teams of learners in four experimental conditions carried out the part-tasks in a predefined order, but differed in the tools they received. Teams in the causal-only and simulation-only conditions received either a causal or a simulation tool for both part-tasks. Teams in the causal-simulation and simulation-causal conditions received both tools in suited and unsuited order respectively. Results revealed that teams using the tool suited to each part-task constructed more task appropriate representations and were better able to share and negotiate knowledge. As a consequence, they performed better on the complex learning-task. Although all learners individually gained more domain knowledge, no differences were obtained between conditions.
\end{abstract}

(c) 2012 Elsevier Ltd. All rights reserved.

\section{Introduction}

There has been a recent surge in the interest of educational researchers for studying the effects of computer supported tools for fostering complex learning (Lazakidou \& Retalis, 2010; Sharples, 2010; Slof, Erkens, Kirschner, Jaspers, \& Janssen, 2010; Zydney, 2010). Complex learning is often regarded as necessary to carry out the activities endemic to modern real-life tasks which are complex because they (1) cannot be described in full detail, (2) give no certainty about what the best solution is, and (3) require different perspectives on the problem and the problem-solving strategy for their solution (Jonassen, 2003; Spector, 2008). To this end, educational approaches such as collaborative problem-solving are increasingly incorporated into training programs and curricula. The premise underlying this approach is that externalizing one's knowledge, discussing it with peers, and establishing and refining (e.g., specifying and correcting) a team's shared understanding of the problem and problem-domain beneficially affects learning (Hmelo-Silver, Duncan, \& Chinn, 2007; Johnson \& Johnson, 2009; Kirschner, Paas, \& Kirschner, 2009). That is, teams and individuals may acquire knowledge and skills which can be effectively

* Corresponding author. Address: University of Groningen, Faculty of Behavioral and Social Science, Unit Teacher Education, P.O. Box 800, 9700 AV Groningen, The Netherlands. Tel.: +31 (0)50 3636611.

E-mail address: B.Slof@rug.nl (B. Slof). transferred to and applied in different situations. Prior research has shown that collaboratively constructing, adjusting and discussing (domain-specific) representations may beneficially affect complex learning-task performance (Nesbit \& Adesope, 2006; Van Meter \& Garner, 2005; Vekiri, 2002). Due to a representational tools' ontology (i.e., its objects, relations, and rules for combining objects and relations) each tool provides a specific sort of representational guidance making certain concepts and/or interrelationships (e.g., causal or mathematical) more salient than others (Fischer, Bruhn, Gräsel, \& Mandl, 2002; Suthers, 2006). Using such tools could foster understanding and learning-task performance because learners are stimulated to carry out learning activities such as (1) selecting relevant information, (2) organizing concepts into coherent structures, (3) relating information to prior understanding, (4) determining knowledge and comprehension gaps, and (5) generating new ideas, questions and plans (Ainsworth, 2006; Hilbert \& Renkl, 2008; Stull \& Mayer, 2007). Furthermore, a shared representation represents learners' current conceptions and ideas about the domain content and the learning-task. In their discussions, learners can easily refer to the representation enabling learners to create shared understanding of these different viewpoints and negotiate about them (Erkens \& Janssen, 2008; Mercer, Littleton, \& Wegerif, 2004; Mühlpfordt \& Stahl, 2007).

Although the educational benefits of representational tools are widely recognized, some studies report mixed or even negative findings and, thus, question how and why such tools might foster 
complex learning (Bera \& Liu, 2006; Elen \& Clarebout, 2007; Lee \& Nelson, 2005; Leutner, Leopold, \& Sumfleth, 2009). The research reported on here addresses this by first describing several pitfalls regarding the design of representational tools aimed at fostering complex learning. Thereafter an instructional approach - representational scripting - is introduced and its effects on the collaborative problem-solving process and learning in business-economics are examined.

\section{Pitfalls in designing representational tools to foster complex learning}

When solving complex problems learners usually have to carry out the following activities: (1) determining what the problem to be solved is, (2) proposing possible multiple solutions to the determined problem, (3) judging the suitability of the different solutions and (4) reaching the solution (Bigelow, 2004; Van Bruggen, Boshuizen, \& Kirschner, 2003). To do all of this, multiple perspectives of the problem domain are required because different representations initiate different kinds of operators which act to produce new information supporting problem solvers in coming to suitable solutions to problems (Frederiksen \& White, 2002; Jonassen, 2003; Kozma, 2003). Qualitative representations represent the concepts underlying a particular domain and the inference rules which interrelate them and, thus, give them meaning. These representations stimulate reasoning about the concepts, their underlying causal principles, and the circumstances under which those principles can legitimately be applied, enabling problem solvers to effectively define the problem and propose multiple solutions for solving it (Jonassen \& Ionas, 2008; Löhner, Van Joolingen, \& Savelsbergh, 2003). Quantitative representations represent the formalism(s) underlying a particular domain to describe the definitions of concepts and their functional relationships, for example via algebraic equations in the domain of business-economics. Such representations stimulate reasoning about the concepts and their mathematical relationships, enabling evaluation of the effects of proposed solutions and, thus, reaching a solution (Kollöffel, Eysink, \& De Jong, 2010; Ploetzner, Fehse, Kneser, \& Spada, 1999).

Problematic here is that specific representational tools, each with its specific ontology, guide learners in constructing and discussing specific representations of the domain and are, thus, not appropriate for carrying out all aspects of a complex learning task (Ainsworth, 2006; Bodemer \& Faust, 2006; Schnotz \& Kürschner, 2008). When the design of the tool is incongruent with the demands of one or more part-tasks this should negatively affect the learner's performance of a complex learning-task (Slof et al., 2010; Van Bruggen et al., 2003). To evoke elaborate and meaningful discussions about the domain requires a representational tool that (1) is in line with its users' capabilities and intentions, and (2) makes clear what its users can and should do with it (Kirschner, Martens, \& Strijbos, 2004; Veldhuis-Diermanse, 2002). If this is not the case, then learners might experience at least two difficulties when using them.

First, part-task related difficulties may arise when learners do not have a realistic idea of the concepts and relationships they must use and how they should relate them to the problem. Due to this, learners experience difficulties in constructing and interpreting their representations and, thus, in acquiring a well-developed understanding of the domain (Ainsworth, 2006; Bodemer \& Faust, 2006). Furthermore, learners might see constructing the representation as an additional task-demand instead of as support. When this is the case, after the concepts are interrelated in the representation, learners pay no further attention to the representation and, therefore, do not apply it to complete their learning-task (De Simone, Schmid, \& McEwan, 2001; Van Amelsvoort, Andriessen, \& Kanselaar, 2007).
Second, learners in CSCL-environments often use multiple tools (e.g., chat tools, representational tools) in a non-sequential way which complicates tracking each others' knowledge, ideas, and actions (Mühlpfordt \& Stahl, 2007; Suthers, Girardeau, \& Hundhausen, 2003). When learners are unable to interpret conveyed messages properly and relate them to each other, they are hindered in carrying out their communicative activities (i.e., coordinating their collaboration process; see Barron, 2003; Erkens \& Janssen, 2008). Important here is that the provided representational tools support learners in coordinating their collaboration process by carrying out communicative activities. That is, learners have to make their own knowledge and ideas explicit to other team members. When made explicit, learners must try to maintain a shared topic of discourse (i.e., achieve a common focus) and repair that focus if they notice focus divergence. Understanding and relating the relevance of individual messages may be hard when learners are simultaneously discussing different topics. Learners should, therefore, coordinate their topic of discourse by focusing (Clark \& Brennan, 1991; Erkens \& Janssen, 2008). Since not all concepts, principles, and procedures are relevant for carrying out a specific part-task learners also must maintain the coherence and consistency of their shared understanding by checking (Van Amelsvoort et al., 2007; Van Boxtel, 2004). Furthermore, learners must come to an agreement about relevant concepts, principles and procedures. Through argumentation they can try to change their partners' viewpoint to arrive at the best way to carry out a part-task or at a definition of concepts acceptable for all. In this argumentation process they try to convince the other(s) by elaborating on their own point of view, and by explaining, justifying and accounting (Ding, 2009; Jeong \& Joung, 2007). When the tools do not facilitate learners to properly coordinate their activities, this hinders them from elaborating on and discussing the content of the domain meaningfully. Whether learners can have such discussions depends on how easily they can refer and relate their contributions to those of others. This 'deictic referencing' is hard when the design of the representational tool is incongruent with the demands and activities of a specific learning task (Slof et al., 2010; Van Bruggen et al., 2003).

\section{Representational scripting}

\subsection{Design principles}

To address the abovementioned pitfalls, it might be beneficial if learners are provided with different representational tools for which the representational guidance of each tool is congruent (i.e., ontologically matched) with the demands of each part-task. Integrating scripting with the availability of multiple representational tools - representational scripting - sequences the different part-task demands, makes them explicit and tailors the congruency of the tools' representational guidance to the part-task demands. Representational tools are meant to support learners in gradually acquiring a well-developed understanding of the knowledge domain by facilitating the construction of qualitative as well as quantitative domain-specific representations. Scripting is employed to ensure proper alignment of the tool, its use, and the part-task demands (Dillenbourg, 2002; Kollar, Fischer, \& Slotta, 2007). According to Dillenbourg, a script is "a set of instructions regarding how the team members should interact, how they should collaborate and how they should solve the problem" (2002, p. 64). Such scripting entails the segmentation of a complex problem in distinct phases with distinct purposes for each phase of the problem-solving process. The script structures the complex learning-task by dividing it into a sequence of ontologically distinct problem phases so that they can be foreseen with representational tools congruent to the part-task demands and activities required 
for each phase. This should actively engage learners in a process of making sense of the domain in question by articulating and discussing multiple perspectives on the problem and of the problem-solving strategy (Hmelo-Silver et al., 2007; Ploetzner et al., 1999).

\subsection{Fostering complex learning in business-economics}

In the research reported on here, learners collaborated on solving a case-based business-economics problem in which they had to advise an entrepreneur about changing the business strategy to increase profits. To gain insight into the part-tasks and their required domain-specific representations, a learning-task analysis (Anderson \& Krathwohl, 2001) was conducted. Based on these insights, the sequence and demands of the part-tasks were specified and part-task congruent representational tools were developed (see Table 1).

In the problem-solution phase learners, first, have to determine what the problem is and what the most important factors are for its solution. Then they have to formulate possible business-strategy changes (i.e., interventions) and elucidate how the changes might solve the problem (i.e., problem-solution) by describing how the changes affect outcomes (i.e., company result). The representational tool should, thus, facilitate construction and discussion of a causal problem-representation by causally relating the concepts to each other and to possible interventions. Fig. 1 shows an expert's qualitative domain-specific representation. The causal representational tool facilitates representing the concepts, the interventions and their causal interrelationships. Selecting relevant concepts and interventions and causally relating them supports the effective exploration of the solution space and, thus, of finding multiple solutions to the problem. Learners receiving such a tool could, for example, make explicit that an intervention such as "receiving a rebate from a supplier" affects the "total variable costs" which in turn via "actual sales" affects the "cost price". Through gradually increasing learners' understanding of the underlying qualitative principles governing the domain, it should be easier for them to come up with an intervention that will solve the problem.

In the solution-evaluation phase learners have to determine the financial consequences of their proposed interventions and

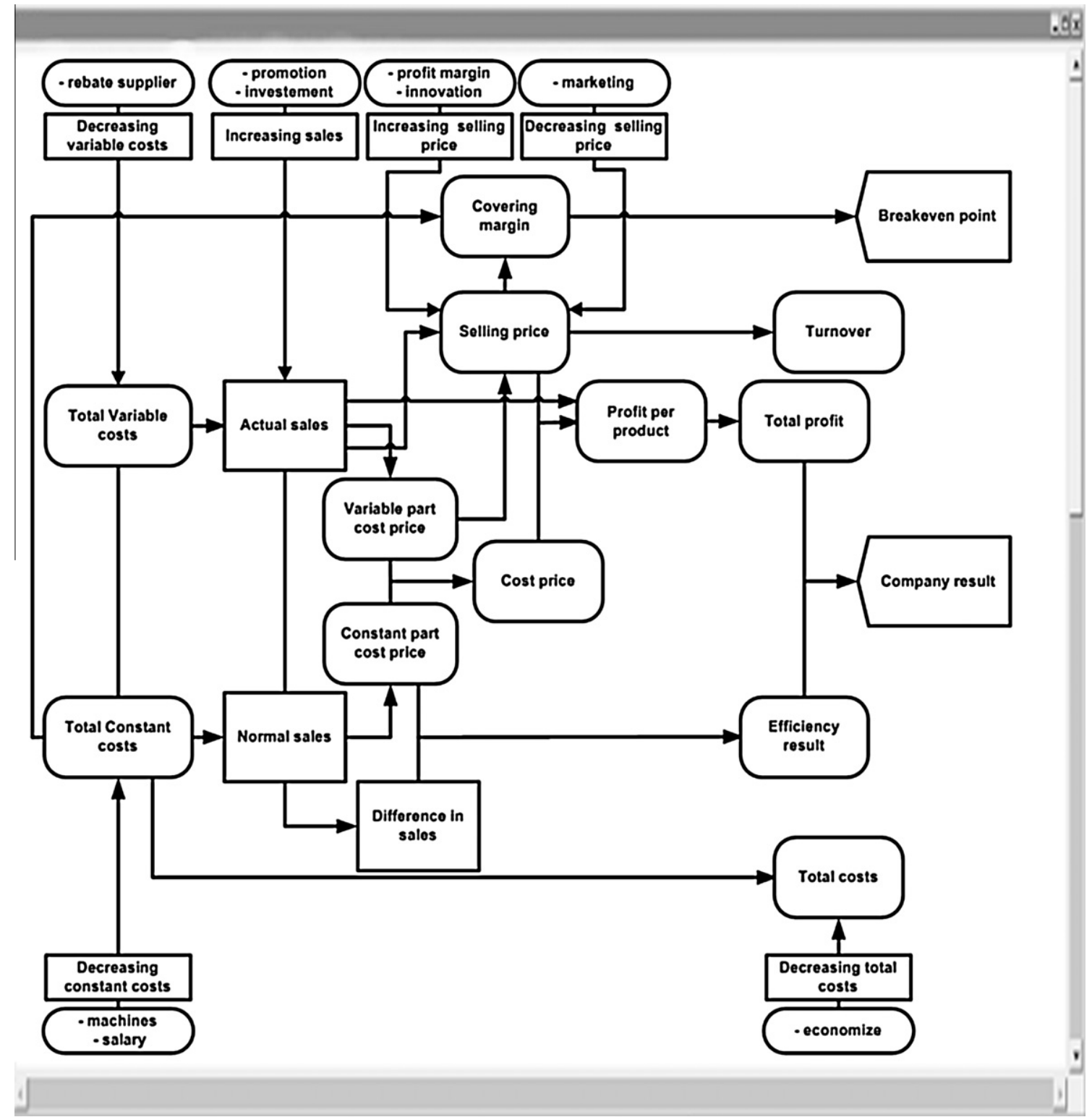

Fig. 1. Expert's qualitative domain-specific representation. 
Table 1

Matching the representational tools' guidance to the task demands of each problem phase.

\begin{tabular}{|c|c|c|c|}
\hline Problem phase & Task demands & Representational tool & Representational guidance \\
\hline Problem-solution & $\begin{array}{l}\text { (a) Defining the problem } \\
\text { (b) Proposing multiple solutions to the problem }\end{array}$ & Causal & $\begin{array}{l}\text { Representing and discussing causal relationships } \\
\text { between the concepts and the possible solutions }\end{array}$ \\
\hline Solution-evaluation & $\begin{array}{l}\text { (a) Determining suitability of the solutions } \\
\text { (b) Coming to a definitive solution to the problem }\end{array}$ & Simulation & $\begin{array}{l}\text { Representing and discussing mathematical } \\
\text { relationships between the concepts and enabling } \\
\text { manipulation of their values }\end{array}$ \\
\hline
\end{tabular}

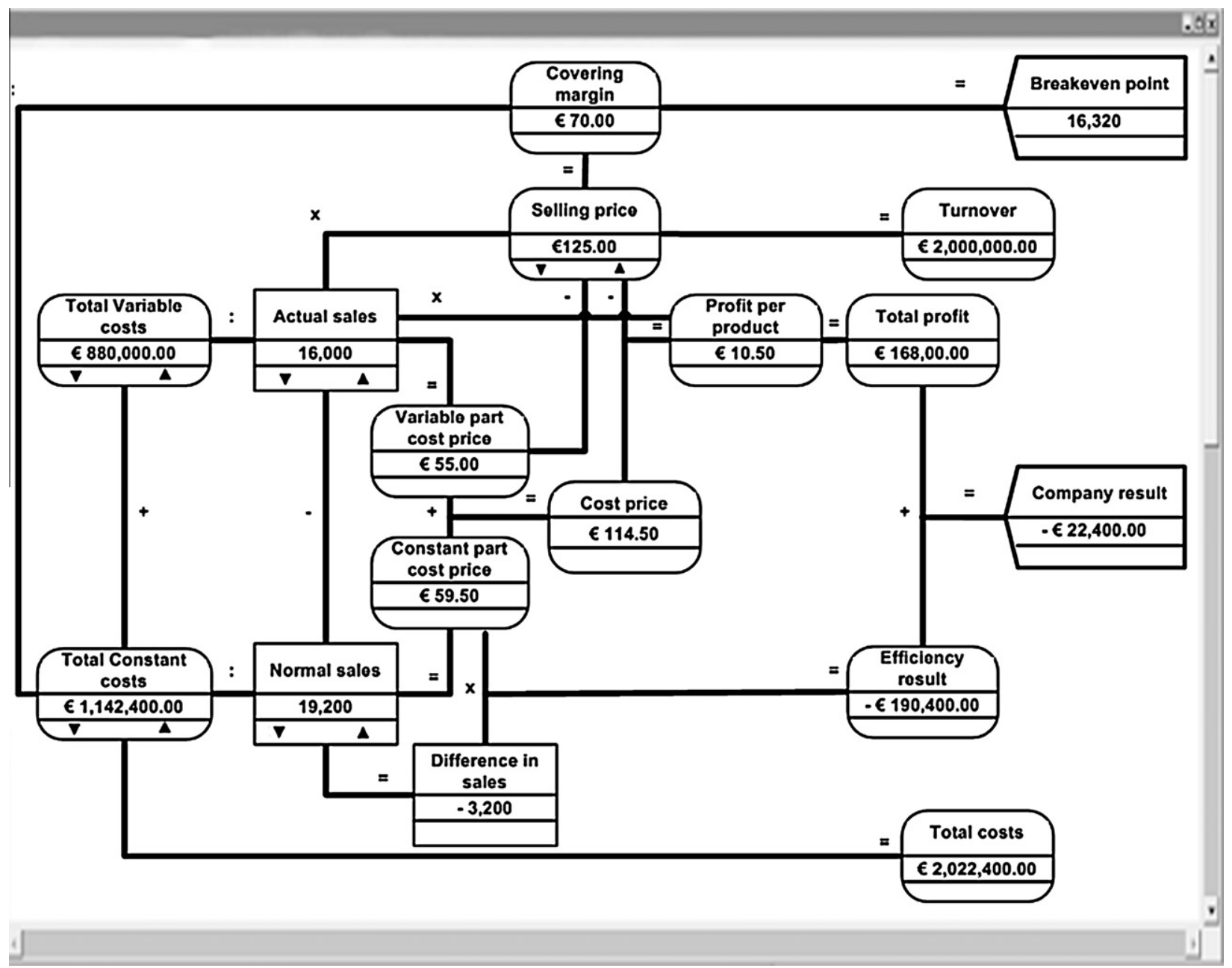

Fig. 2. Expert's quantitative domain-specific representation.

formulate a definitive advice by discussing the suitability of the different interventions with each other. The representational tool must, therefore, facilitate construction and discussion of a quantitative representation by specifying the relationships as algebraic equations. Fig. 2 shows a quantitative domain-specific representation as seen by an expert. The simulation representational tool facilitates representing the concepts and their mathematical interrelationships. Selecting relevant concepts and specifying the interrelationships as algebraic equations supports evaluating the effects of the proposed interventions and, thus, in choosing a suitable advice. Learners receiving such a tool could, for example, construct a representation to simulate how an intervention such as "receiving a rebate from a supplier" affects the "total variable costs" and whether this affects the "cost price". By manipulating the input values, the values of all other related concepts are automatically computed. Since such quantitative representations can only be properly understood and applied when learners have a well-developed qualitative understanding of the domain, this kind of support is only appropriate for carrying out this type of part-task.

\section{Design and research questions}

To study the effects of representational scripting, four experimental conditions were defined by matching, partly matching or mismatching the tool's representational guidance to the demands of each problem phase (Table 2).

Scripting the problem-solving process sequenced and made the part-task demands explicit. These demands are (1) defining the problem and proposing multiple solutions, and (2) determining the suitability of the solutions and coming to a definitive solution. Teams in all conditions had to carry out the part-tasks in this predefined order, but differed in the representational tool they 
Table 2

Overview of the experimental conditions.

\begin{tabular}{|c|c|c|c|}
\hline \multirow[t]{2}{*}{ Conditions } & \multicolumn{2}{|c|}{ Problem phases and provided representational tools } & \multirow[t]{2}{*}{ Match/mismatch } \\
\hline & Problem-solution & Solution-evaluation & \\
\hline Causal-only & Causal tool & Causal tool & Match for the solution phase only \\
\hline Simulation-only & Simulation tool & Simulation tool & Match for the evaluation phase only \\
\hline Simulation-causal & Simulation tool & Causal tool & Mismatch for all problem phases \\
\hline Causal-simulation & Causal tool & Simulation tool & Match for all problem phases \\
\hline
\end{tabular}

received. Teams in the matched (i.e., causal-simulation) and the mismatched (i.e., simulation-causal) conditions received both representational tools in a phased order. The difference between these conditions was that the tools were part-task congruent or not. In the simulation-causal condition the teams received both tools, but in an order that was mismatched to the part-task demands (i.e., simulation tool for the definition phase and causal tool for the evaluation phase). In contrast, teams in the causal-simulation condition received representational tools considered to be wellsuited to the part-task demands of each problem phase. In the partly matched conditions (i.e., causal-only and simulation-only), teams received either a causal or a simulation tool for carrying out both part-tasks and for constructing the part-task related representations. The tools' representational guidance matched only one of the part-task demands. Due to the presumed match between tools' representational guidance and all part-tasks demands (i.e., representational scripting), it was hypothesized that teams in the matched condition, in comparison to teams in the other conditions, would:

(H1) Demonstrate a qualitatively better problem solving process, evidenced by

(a) Constructing representations that are more suited for carrying out the part-tasks,

(b) Carrying out more communicative activities.

(H2) Acquire more individual and team learning gains, evidenced by

(a) Scoring higher on the individual post-knowledge test

(b) Proposing better solutions and a formulating a better definitive advice to the team complex learning task.

\section{Method}

\subsection{Participants}

Participants were students from six business-economics classes in three secondary schools in the Netherlands. The total sample consisted of 102 students (61 male, 41 female; mean age $=15.7$ years; $S D=.56, \operatorname{Min}=14, \operatorname{Max}=17$ ). Since the collaborative problem solving task was developed in cooperation with their teachers it is regarded as a suited pedagogical activity for the students at that point in the curriculum. To examine the effects of representational scripting students were, within classes, randomly assigned to 34 teams; nine triads in the causal-only, simulationonly and simulation-causal conditions and seven triads in the causal-simulation condition. By doing so, not only the value of qualitative (i.e., causal-only condition) and quantitative representations (i.e., simulation-only condition) for carrying out complex learning-tasks but also their interrelationship (i.e., simulationcausal and causal-simulation conditions) can be examined. Furthermore, through verifying the assumed beneficial effects of representational scripting, proper support for carrying out complex learning-tasks in business-economics might be established and implemented in future educational programs.

\subsection{CSCL-environment}

The teams worked in a CSCL-environment called Virtual Collaborative Research Institute (VCRI; Jaspers, Broeken, \& Erkens, 2005; see Fig. 3), a groupware application for supporting the collaboratively carrying out problem-solving tasks. For this study, the tools in VCRI were augmented with representational scripting. At the start of the first lesson, all diagram boxes - representing the different concepts/solutions - were placed on the left side of the Representational tool so team members could select them when they wanted to add a new causal or mathematical relationship. The Model menu of the representational tool enabled team members to construct and adjust their representations by adding or deleting relationships. The Chat tool enabled synchronous communication and supported team members in externalizing and discussing their knowledge and ideas about the domain content and their problemsolving strategy. The chat history is automatically stored and can be re-read by the team members. The Co-writer is a shared textprocessor where team members could collaboratively formulate and revise their decisions concerning the part-tasks. The Notes tool is an individual notepad that allowed team members to store information and structure their own knowledge and ideas before making them explicit to the other members. In the Assignment menu, team members can find the description of the task/part-tasks. Furthermore, additional information sources such as a definition list, formula list, and problem-solving clues were also available here. The Status bar is an awareness tool that displayed which team members were logged into the system and which tool a member was using at any specific moment.

All teams had to carry out the part-tasks in a predefined order namely starting with the problem-solution phase and ending with the solution-evaluation phase. When the team members agreed that the part-task demands of the first phase were completed, they had to 'close' that phase in the assignment menu. This 'opened' the second phase, which had two consequences for all team members, namely they were instructed to carry out the part-task demands of this phase and then revise their representation of the domain so it concurred with the decisions they made when carrying out this part-task. Teams in the causal-only and simulation-only conditions were facilitated in elaborating on their previously constructed representation. Since those teams kept the same representational tool, all concepts and their relationships remained visible and could be revised as the team members deemed appropriate for carrying out the task demands of the following phase. Teams in the simulationcausal and causal-simulation conditions were facilitated in acquiring and applying a different qualitative or quantitative perspective of the domain. Their previously selected concepts remained visible and they were instructed to replace the relationships by specifying them in either a causal manner (i.e., simulation-causal) or as algebraic equations (i.e., causal-simulation) with the aid of their new tool.

\subsection{Procedure}

All 34 teams spent four, 45-min lessons solving the problem during which learners worked on separate computers. Before the 


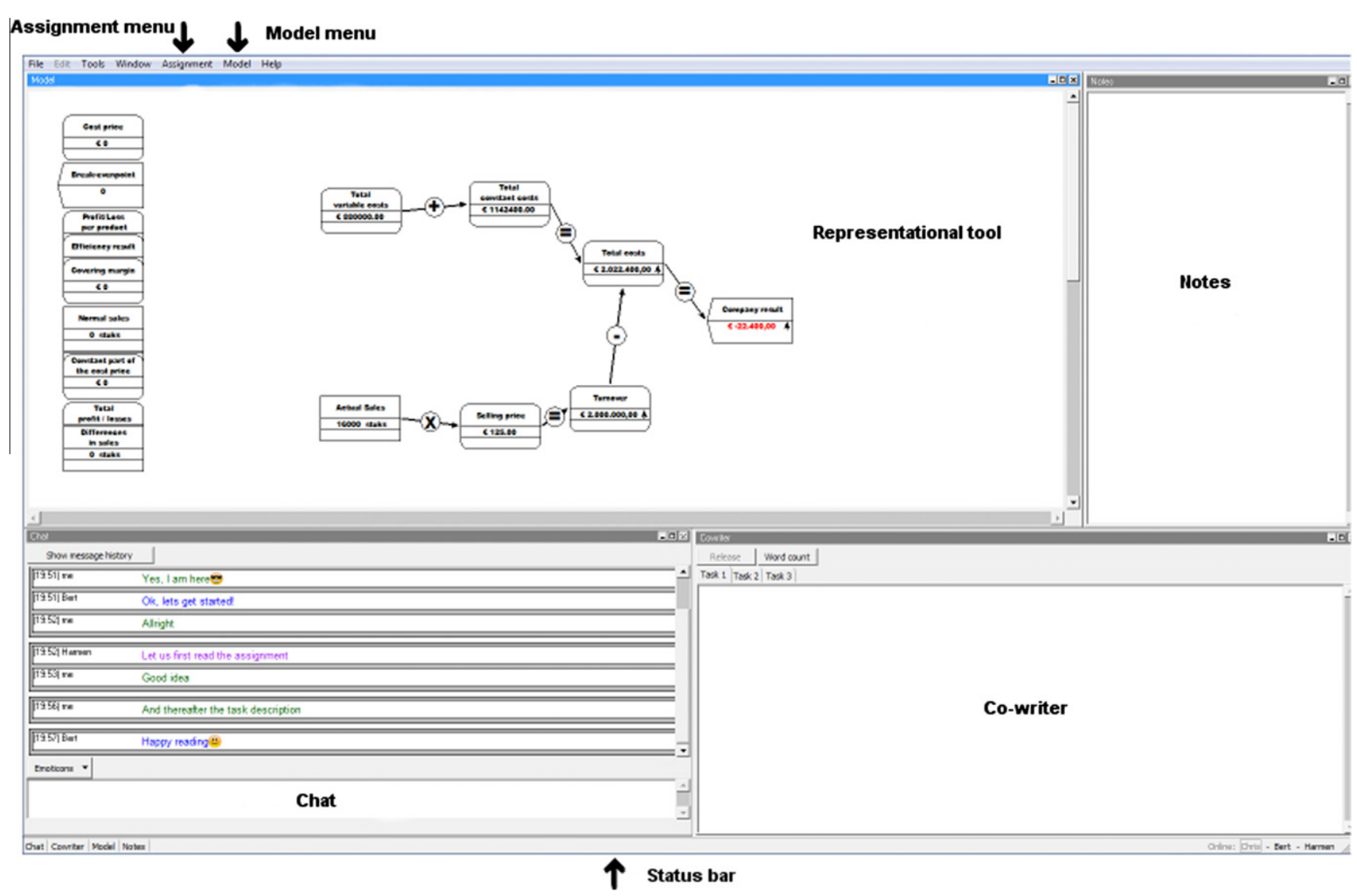

Fig. 3. Screenshot of the VCRI-environment (simulation representational tool).

first lesson, learners received an instruction about the team composition, the complex learning-task and the CSCL-environment. The instruction made clear that their score on the post-knowledge test and the complex learning-task would serve as a grade affecting their GPA. Learners worked on the problem in the computer classroom and all actions (e.g., contributions to the chat-discussion, constructed representations, and decisions concerning the parttasks) were logged. During the lessons, the teacher was on standby for task-related questions and a researcher was present for technical support.

\subsection{Variables and analyses}

To gain insight in how and why the representational scripting affects the collaborative problem-solving process and leaning in CSCL an process oriented and an effect oriented research approach were combined (Dennen, 2008; Fischer et al., 2002). Data on both learning process (i.e., constructed representations and communicative activities) and learning results (i.e., individual learning gains and team learning-task performance) were collected and analyzed. Since there were specific directions of the results expected all analyses are one-tailed.

\subsubsection{Constructed representations}

A content analysis was conducted on the phase-related representations to examine the quality of the constructed representations. To this end, the representations were selected at the end of each problem phase just before a phase was 'closed', and transferred from the log-files using the Multiple Episode Protocol Analysis program (MEPA; Erkens, 2005). Then they were coded with respect to how many concepts and relationships were represented and whether they were represented correctly. It should be noted that the (nine) possible interventions were also coded as concepts since learners receiving the causal tool were facilitated in representing them. When a concept was related to multiple other concepts, it received a code for each relationship and could, thus, be coded several times. The coding was done automatically with a MEPA-filter which makes use of 364 'if-then' decision rules containing explicit references to the concepts, the relationships and its correctness (based on the expert's domain-specific representations, see Figs. 1 and 2 ).

The quality of the visualizations was examined through conducting independent-samples $t$-tests concerning the number of concepts and interrelationships that were represented in each of the two problem phases and whether they were represented correctly.

\subsubsection{Communicative activities}

Measurement of the communicative activities was aimed at gaining insight into how learners coordinated their collaborative problem-solving process. As can be seen in Table 3 each utterance was coded with respect to the type of dialog act used. A dialog act was regarded as a communicative action which is elicited for a specific purpose representing a specific function in the dialog (Mercer et al., 2004). Coding was based on the occurrence of characteristic words or phrases (i.e., discourse markers; see Schiffrin, 1987) indicating the communicative function of an utterance. This was done automatically with a MEPA-filter using 1250 'if-then' decision rules using pattern matching to find typical words or phrases. When compared to hand-coding, an overall agreement of $79 \%$ was reached and a Cohen's Kappa of .75 was found (Erkens \& Janssen, 2008). The coordinating activities of focusing, checking and argumentation are indicated by the occurrence of specific dialogs acts.

The effect of condition on communicative activities was examined through conducting multi-level analysis (MLA) which 
Table 3

Coding concerning learners' communicative activities.

\begin{tabular}{|c|c|c|c|}
\hline Activities & Dialog act & Description & $\begin{array}{l}\text { Example discourse } \\
\text { marker }\end{array}$ \\
\hline \multirow[t]{5}{*}{ Focusing } & $\begin{array}{l}\text { Elicitative } \\
\text { proposal for } \\
\text { action }\end{array}$ & $\begin{array}{l}\text { Proposition for } \\
\text { action }\end{array}$ & $\begin{array}{l}\text { Let's start with the } \\
\text { first part-task? }\end{array}$ \\
\hline & $\begin{array}{l}\text { Elicitative } \\
\text { question open }\end{array}$ & $\begin{array}{l}\text { Open question } \\
\text { with a lot of } \\
\text { alternatives }\end{array}$ & $\begin{array}{l}\text { Shall we fist look at } \\
\text { the description of the } \\
\text { assignment or at the } \\
\text { description of the } \\
\text { part-tasks? }\end{array}$ \\
\hline & $\begin{array}{l}\text { Imperative } \\
\text { action }\end{array}$ & $\begin{array}{l}\text { Command to } \\
\text { perform an } \\
\text { action }\end{array}$ & $\begin{array}{l}\text { Finish the decision to } \\
\text { the second part-task }\end{array}$ \\
\hline & $\begin{array}{l}\text { Imperative } \\
\text { focus }\end{array}$ & $\begin{array}{l}\text { Command for } \\
\text { attention }\end{array}$ & $\begin{array}{l}\text { Look at the } \\
\text { representational tool! }\end{array}$ \\
\hline & $\begin{array}{l}\text { Elicitative } \\
\text { question verify }\end{array}$ & $\begin{array}{l}\text { Question that } \\
\text { can only be } \\
\text { answered with } \\
\text { yes or no }\end{array}$ & $\begin{array}{l}\text { Do you refer to the } \\
\text { company result?? }\end{array}$ \\
\hline \multirow[t]{4}{*}{ Checking } & $\begin{array}{l}\text { Elicitative } \\
\text { question set }\end{array}$ & $\begin{array}{l}\text { Question } \\
\text { where the } \\
\text { alternatives } \\
\text { are already } \\
\text { given (set) }\end{array}$ & $\begin{array}{l}\text { Are you for or against } \\
\text { increasing sales? }\end{array}$ \\
\hline & $\begin{array}{l}\text { Responsive } \\
\text { confirm }\end{array}$ & $\begin{array}{l}\text { Confirming } \\
\text { answer }\end{array}$ & $\begin{array}{l}\text { Yes, we indeed should } \\
\text { start a promotion- } \\
\text { campaign }\end{array}$ \\
\hline & $\begin{array}{l}\text { Responsive } \\
\text { deny }\end{array}$ & $\begin{array}{l}\text { Denying } \\
\text { answer }\end{array}$ & $\begin{array}{l}\text { No, that is not a good } \\
\text { solution }\end{array}$ \\
\hline & $\begin{array}{l}\text { Responsive } \\
\text { accept }\end{array}$ & $\begin{array}{l}\text { Accepting } \\
\text { answer }\end{array}$ & Oh, Yes that OK \\
\hline \multirow[t]{6}{*}{ Argumentation } & $\begin{array}{l}\text { Argumentative } \\
\text { reason }\end{array}$ & Reason & $\begin{array}{l}\text { Because this solution } \\
\text { does not affect our } \\
\text { costs }\end{array}$ \\
\hline & $\begin{array}{l}\text { Argumentative } \\
\text { against }\end{array}$ & Objection & $\begin{array}{l}\text { But this would cost } \\
\text { more money }\end{array}$ \\
\hline & $\begin{array}{l}\text { Argumentative } \\
\text { conditional }\end{array}$ & Condition & $\begin{array}{l}\text { If we increase the } \\
\text { selling price... }\end{array}$ \\
\hline & $\begin{array}{l}\text { Argumentative } \\
\text { then }\end{array}$ & Consequence & $\begin{array}{l}\text { Then the cost price } \\
\text { decreases }\end{array}$ \\
\hline & $\begin{array}{l}\text { Argumentative } \\
\text { disjunctive }\end{array}$ & Disjunctive & $\begin{array}{l}\text { We can increase the } \\
\text { actual sales through a } \\
\text { promotion-campaign } \\
\text { or by decreasing the } \\
\text { selling price or by... }\end{array}$ \\
\hline & $\begin{array}{l}\text { Argumentative } \\
\text { conclusion }\end{array}$ & Conclusion & $\begin{array}{l}\text { Thus we can conclude } \\
\text { that the third solution } \\
\text { leads to the best } \\
\text { company result }\end{array}$ \\
\hline
\end{tabular}

addresses the statistical problem of non-independence often associated with CSCL research (Kenny, Kashy, \& Cook, 2006). Many statistical techniques (e.g., $t$-test, ANOVA) assume score-independence and violating this assumption compromises interpretation of the output of the analyses (e.g., $t$-value, standard error, $p$-value). Nonindependence was determined by computing the intraclass correlation coefficient and its significance (Kenny et al., 2006) for all dependent variables relating to learner interaction. Its value demonstrated non-independence $(\alpha<.05)$ for all tests, justifying MLA use. MLA entails comparing the deviance of an empty model and a model with one or more predictor variables to compute a possible decrease in deviance. The latter model is considered better when there is a significant decrease in deviance from the empty model (tested with a $\chi^{2}$-test). Almost all reported $\chi^{2}$-values were significant $(\alpha<.05)$ and, therefore, the estimated parameters of these predictor variables (i.e., effects of condition) were tested for significance.

\subsubsection{Individual leaning gains}

Recall and understanding of the knowledge domain was measured with a pre-knowledge test (20 items, $\alpha=.60$ ) and a post-
Table 4

Items and reliability of complex learning-task performance.

\begin{tabular}{|c|c|c|c|}
\hline Criteria & Description & Items & $\alpha$ \\
\hline Suitability & $\begin{array}{l}\text { Whether the teams' decisions were suited to the } \\
\text { different part-tasks }\end{array}$ & 6 & .65 \\
\hline Elaboration & $\begin{array}{l}\text { Number of different business-economics } \\
\text { concepts or financial consequences incorporated } \\
\text { in the decisions to the different part-tasks }\end{array}$ & 6 & .47 \\
\hline Justification & $\begin{array}{l}\text { Whether the teams justified their decisions to } \\
\text { the different part-tasks }\end{array}$ & 6 & .51 \\
\hline Correctness & $\begin{array}{l}\text { Whether the teams used the business- } \\
\text { economics concepts and their interrelationships } \\
\text { correctly in their decisions to the different part- } \\
\text { tasks }\end{array}$ & 6 & .55 \\
\hline Continuity & $\begin{array}{l}\text { Whether the teams made proper use of the } \\
\text { decisions from the prior problem phase }\end{array}$ & 1 & - \\
\hline $\begin{array}{l}\text { Quality } \\
\text { advice }\end{array}$ & $\begin{array}{l}\text { Whether the teams gave a proper definitive } \\
\text { advice } \\
\text { - Number of business-economics concepts } \\
\text { incorporated in the advice } \\
\text { - Number of financial consequences incorpo- } \\
\text { rated in the advice } \\
\text { - Whether the definitive advice conformed to } \\
\text { the guidelines provided }\end{array}$ & 3 & .71 \\
\hline Total score & $\begin{array}{l}\text { Overall score on the complex learning-task } \\
\text { performance }\end{array}$ & 28 & .84 \\
\hline
\end{tabular}

knowledge test (20 items, $\alpha=.65$ ). The multiple-choice items in both tests were drawn from a total pool of items and equally divided across the three knowledge dimensions (i.e., factual, conceptual and procedural knowledge, see Anderson \& Krathwohl, 2001). Because of the low reliability of the scores on the subscales of both knowledge tests (e.g., $\alpha \leqslant .50$ ) learner recall and understanding of the different knowledge dimensions was not tested. In the analyses, thus, only the overall scores on the pre-knowledge test and the post-knowledge test were used.

The effect of condition on individual learning gains was examined through conducting MLA.

\subsubsection{Team complex learning-task performance}

To examine performance quality, an assessment form for both part-tasks and for the quality of the definitive advice was developed. Table 4 provides a description of the aspects on which the decisions were evaluated, the number of items, and their internal consistency scores (i.e., Cronbach's alpha). All 28 items could be coded as "0" (wrong), "1" (adequate) or "2" (good); the higher the code, the higher the quality of the decision. Teams could, thus, achieve a maximum score of 56 points for their complex learningtask performance ( 28 items $\times 2$ points) and a minimum of 0 points. The internal consistency score for the whole complex learning-task performance was .84 .

The effect of condition was examined through conducting a one-way ANOVA on the total performance score that the teams received. Planned orthogonal contrasts were constructed to examine whether a significant difference could be found between the (1) partly matched conditions and the matched/mismatched conditions), (2) matched condition (i.e., causal-simulation) and the mismatched condition (i.e., simulation-causal), and (3) two partly matched conditions (i.e., causal-only and simulation-only).

\section{Results}

\subsection{Constructed representations}

The content analyses concerning the quality of the constructed representations in relation to the task demands of the problem phases revealed two different patterns (see Fig. 4). That is, teams in the matched (i.e., causal-simulation) and non-matched (i.e., sim- 

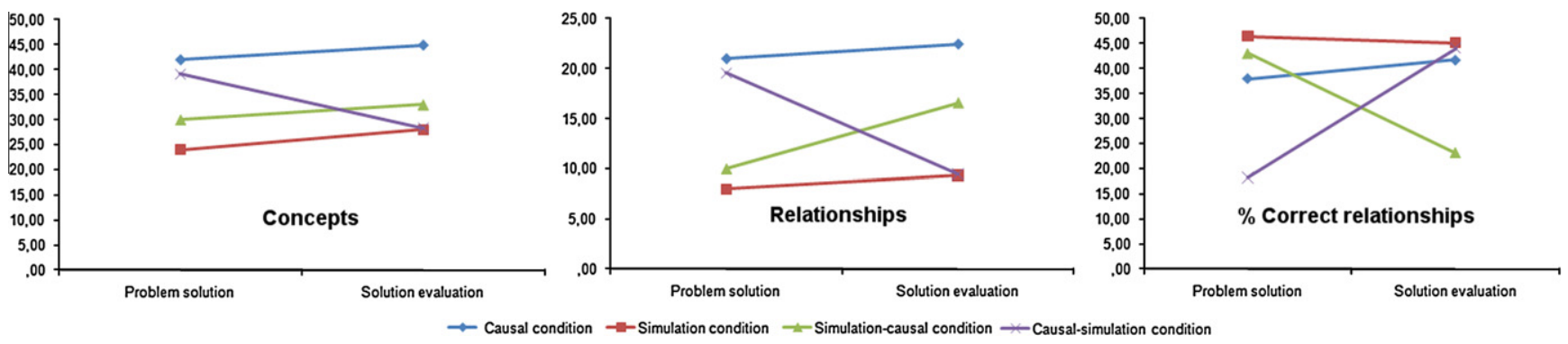

Fig. 4. Content analyses for effects of condition concerning representational tool use.

ulation-causal) conditions had a more diverse pattern in representing the domain content compared to teams in the partly matched conditions (i.e., causal-only and simulation-only). The former teams adjusted their domain-specific representations more often when carrying out the part-tasks. To gain more insight into these patterns, specific comparisons between conditions were made. These analyses revealed several differences between conditions. First, teams in the causal-simulation condition, compared to teams in the simulation-causal condition, significantly represented (1) more relationships during the problem-solution phase $(t(14)=$ 2.77, $p=.03$ ) but made more errors in representing those relationships $(t(14)=4.18, p=.00)$, (2) fewer relationships during the solution-evaluation phase $(t(14)=-2.29, p=.05)$ but made less errors in representing the relationships $(t(14)=-3.59, p=.00)$. Second, teams in the partly matched conditions showed a stable pattern in representing domain content, teams in the causal-only condition overall represented significantly more concepts $(t(16)=$ 2.56, $p=.02)$ and relationships $(t(16)=4.24, p=.00)$ compared to teams in the simulation-only condition.

Overall, these analyses show that teams using multiple representational tools, in contrast to teams using a single tool, varied more in representing the domain content. This was, however, only beneficial for teams in the causal-simulation condition since they became more selective in representing the concepts and specifying their relationships as algebraic equations.

\subsection{Communicative activities}

Inspection of the means and standard deviations revealed differences between conditions (see Table 5). MLAs revealed that condition was a significant predictor for how learners coordinated their collaborative problem-solving process when comparing learners in the causal-simulation condition to learners in the causal-only $(\beta=79.35, p<.05)$, simulation-only $(\beta=71.96, p<.05)$ and simulation-causal $(\beta=100.59, p<.05)$ conditions (see Table 6$)$. When analyzing the communicative activities separately, several category effects were obtained. First, a significant category effect was found for checking; learners in the causal-simulation condition attended more to guarding the coherence and consistency of their shared understanding of the domain than learners in the causalonly $(\beta=43.69, p<.05)$, simulation-only $(\beta=38.24, p<.05)$ and simulation-causal $(\beta=49.11, p<.01)$ conditions. Second, a significant category effect was found for argumentation; learners in the causal-simulation condition exhibited more argumentative activities than learners in the causal-only $(\beta=24.92, p<.05)$, simulation-only $(\beta=24.28, p<.05)$ and simulation-causal $(\beta=32.97$, $p<.05)$ conditions. Finally, a significant category effect was found for focusing; learners in the causal-simulation condition devoted more attention to coordinate what their topic of discourse was than learners in the simulation-causal condition $(\beta=18.60$, $p<.05)$.

Table 5

Means and standard deviations for differences between conditions concerning communicative activities.

\begin{tabular}{|c|c|c|c|c|}
\hline & $\begin{array}{l}\text { Causal-only condition } \\
\left(n_{\text {learner }}=27\right) \\
M(S D)\end{array}$ & $\begin{array}{l}\text { Simulation-only condition } \\
\left(n_{\text {learner }}=27\right) \\
M(S D)\end{array}$ & $\begin{array}{l}\text { Simulation-causal condition } \\
\left(n_{\text {learner }}=27\right) \\
M(S D)\end{array}$ & $\begin{array}{l}\text { Causal-simulation condition } \\
\left(n_{\text {learner }}=21\right) \\
M(S D)\end{array}$ \\
\hline Coordination & $108.86(70.44)$ & $122.52(78.84)$ & $92.62(56.44)$ & 194.48 (120.67) \\
\hline Focusing & $25.14(17.73)$ & $27.70(19.23)$ & 18.23 (13.19) & $37.14(22.86)$ \\
\hline Checking & 49.45 (30.99) & $57.67(38.60)$ & $46.04(28.18)$ & $95.90(62.88)$ \\
\hline Argumentation & $34.27(27.92)$ & $37.15(26.48)$ & $28.35(20.52)$ & $61.43(40.60)$ \\
\hline
\end{tabular}

Table 6

Estimates for random intercept model for differences between conditions concerning communicative activities.

\begin{tabular}{|c|c|c|c|c|c|c|c|c|}
\hline & \multicolumn{2}{|c|}{ Coordination } & \multicolumn{2}{|c|}{ Focusing } & \multicolumn{2}{|c|}{ Checking } & \multicolumn{2}{|c|}{ Argumentation } \\
\hline & $\beta$ & $S E$ & $\beta$ & $S E$ & $\beta$ & $S E$ & $\beta$ & $S E$ \\
\hline$\gamma_{00}=$ Intercept & 194.48 & 27.54 & 37.14 & 6.03 & 95.90 & 13.15 & 61.43 & 9.18 \\
\hline$\beta_{1}=$ causal-only vs. causal-simulation & $79.35^{*}$ & 37.90 & 11.27 & 8.30 & $43.69^{*}$ & 18.12 & $24.92^{*}$ & 12.66 \\
\hline$\beta_{2}=$ simulation-only vs. causal-simulation & $71.96^{*}$ & 36.72 & 9.44 & 8.04 & $38.24^{*}$ & 17.53 & $24.28^{*}$ & 12.24 \\
\hline$\beta_{3}=$ simulation-causal vs. causal-simulation & $100.59^{*}$ & 36.80 & $18.60^{*}$ & 8.05 & $49.11^{* *}$ & 17.58 & $32.97^{*}$ & 12.27 \\
\hline \multicolumn{9}{|l|}{ Variance } \\
\hline Team level & 3052.03 & & 149.33 & & 887.11 & & 463.24 & \\
\hline Individual level & 4290.99 & & 204.58 & & 914.14 & & 435.48 & \\
\hline Deviance & 1059.00 & & 780.80 & & 938.34 & & 876.60 & \\
\hline Decrease in deviance & $34.04^{* *}$ & & $22.53^{* *}$ & & $30.46^{* *}$ & & $27.15^{* *}$ & \\
\hline
\end{tabular}

${ }^{*} p<.05$

** $p<.01$. 
Overall, these analyses show that learners in the causal-simulation condition were better able to establish and maintain shared understanding of the domain and also to argue about it than learners in the other conditions.

\subsection{Individual learning gains}

Inspection of the means and standard deviations revealed differences between conditions (see Table 7). A one-way ANOVA showed no significant differences between conditions on the preknowlegde test score $(F(3,92)=0.56, p>.05)$. This means that learners did not significantly differ in the amount of prior knowledge and it was, therefore, not necessary to correct for this. A paired-samples $t$-test showed that the overall post-knowledge test score of 96 learners (not all 102 learners were present when both knowledge tests were administered) was significantly higher than the overall pre-knowledge test score $(t(96)=1.89, p=.00)$. Although there were individual learning gains MLAs, however, revealed no significant differences between learners in the causalsimulation condition and learners in the causal-only $(\beta=0.11$, $p>.05)$, simulation-only $(\beta=0.22, p>.05)$ and simulation-causal $(\beta=0.20, p>.05)$ conditions. Nor were there differences between other conditions.

Overall, these results are not completely in line with the expectations; there were individual learning gains, however, no significant differences between conditions were obtained.

\subsection{Team complex learning-task performance}

Inspection of the means and standard deviations revealed differences between conditions (see Table 8). A one-way ANOVA revealed there was a significant effect of condition on team complex learning-task performance, $F(3,21.50)=7.00, p<.01$, $\omega 2=.33$ (Brown-Forsythe because homogeneity of variance assumption was violated). The constructed planned orthogonal contrasts revealed that teams in the (1) multiple tool conditions significantly outperformed the teams in the single tool conditions, $t(21.61)=3.97, p<.01$ (equal variances not assumed), $r=.65$ (2) matched causal-simulation condition significantly outperformed teams in non-matched simulation-causal condition, $t(15.40)=$ $7.24, p<.01$ (equal variances not assumed), $r=.88$. No significant difference was found between teams in the causal-only and simulation-only conditions, $t(30)=1.50, p>.05, r=.26$. To examine the differences between the non-matched condition and the partly matched conditions, post-hoc tests (Games-Howell) were carried out, revealing no significant differences, $t(16)=1.01, p>.05$, $r=.24$, and $t(16)=1.36, p>.05, r=.32$, respectively. This indicates that team complex learning-task performance in the non-matched simulation-causal condition did not differ from performance in the partly matched causal-only or simulation-only conditions.

Overall, the results show that constructing different kinds of representations is beneficial to constructing only one kind of representation, but that this advantage is only significant when a tools' representational guidance is matched to the task demands of each problem phase.

\section{Discussion}

This study examined how and why scripting learners' use of representational tools (i.e., representational scripting) affects the collaborative problem-solving process and learning in CSCL. The obtained results revealed that teams of learners receiving representational tools that were completely matched to the part-task demands of the problem phases, (i.e., a causal tool followed by a simulation tool) performed better on the complex learning task. That is, those teams formulated better decisions with respect to the part-tasks and came up with better definitive solutions to the problem than teams receiving (1) only a causal or a simulation tool and (2) simulation tool followed by a causal tool. Furthermore, all learners acquired a better understanding of the domain (i.e., differences post-knowledge test and pre-knowledge test), although no significant differences concerning received tools were obtained. Two differences concerning the quality of the learning process were found that might explain how and why representational scripting beneficially affected team complex learning.

First, teams receiving both tools (i.e., causal and simulation tool) adjusted their domain-specific representations to the parttask demands of the problem phases. However, this was only beneficial for teams receiving tools that were matched to the part-task demands (i.e., receiving the causal tool before the simulation tool); they started with the construction of a broad representation and gradually became more selective in representing the concepts and specifying their relationships as algebraic equations. This might have fostered learning, since this is (1) the way that solving such a problem should theoretically be carried out (Van Merriënboer \& Kirschner, 2007) and (2) consistent with prior research

Table 7

Means and standard deviations for differences between conditions concerning the pre-test and post-test scores.

\begin{tabular}{lllll}
\hline Test & $\begin{array}{l}\text { Causal-only condition } \\
\left(n_{\text {learner }}=25\right)\end{array}$ & $\begin{array}{l}\text { Simulation-only } \\
\text { condition }\left(n_{\text {learner }}=25\right) \\
M(S D)\end{array}$ & $\begin{array}{l}\text { Simulation-causal } \\
\text { condition }\left(n_{\text {learner }}=26\right) \\
M(S D)\end{array}$ & $\begin{array}{l}\text { Causal-simulation } \\
\text { condition }\left(n_{\text {learner }}=20\right) \\
M(S D)\end{array}$ \\
\hline Pre-test & $10.63(2.95)$ & $11.20(2.04)$ & $11.44(2.58)$ & $\begin{array}{l}\text { Overall conditions } \\
\left(N_{\text {learner }}=96\right) \\
M(S D)\end{array}$ \\
Post-test & $13.22(2.56)$ & $12.92(2.65)$ & $13.00(2.64)$ & $10.72(2.27)$ \\
$13.02(2.48)$ & $13.11(2.54)$ \\
\hline
\end{tabular}

Table 8

Means and standard deviations for differences between conditions concerning complex learning-task performance.

\begin{tabular}{lccr}
\hline Criteria & $\begin{array}{l}\text { Causal-only } \\
\text { condition }\left(n_{\text {team }}=9\right) \\
M(S D)\end{array}$ & $\begin{array}{l}\text { Simulation-only } \\
\text { condition }\left(n_{\text {team }}=9\right) \\
M(S D)\end{array}$ & $\begin{array}{l}\text { Simulation-causal } \\
\text { condition }\left(n_{\text {team }}=9\right) \\
M(S D)\end{array}$ \\
\hline Suitability & $9.89(2.62)$ & $9.89(1.83)$ & $\begin{array}{l}\text { Causal-simulation } \\
\text { condition }\left(n_{\text {team }}=7\right) \\
M(S D)\end{array}$ \\
Elaboration & $6.22(2.33)$ & $6.33(1.87)$ & $10.00(2.24)$ \\
Justification & $3.00(1.50)$ & $3.11(1.36)$ & $4.22(2.59)$ \\
Correctness & $4.44(1.67)$ & $4.22(1.20)$ & $5.00(1.73)$ \\
Continuity & $1.44(0.73)$ & $1.56(0.53)$ & $5.11(1.54)$ \\
Quality advice & $3.22(1.39)$ & $2.89(1.27)$ & $3.00(0.58)$ \\
Total score & $28.22(7.50)$ & $28.00(4.44)$ & $3.14(1.46)$ \\
\hline
\end{tabular}


indicating that there is a strong relationship between the quality of constructed representations and task performance (Greene, 1989; Van Meter \& Garner, 2005). In contrast, teams who had access to only one of the representational tools (i.e., causal or simulation tool) showed a stable pattern in representing the domain content. Those teams either represented many concepts and relationships (i.e., causal tool) or they did not (i.e., simulation tool) and were, thus, less occupied with fine-tuning their representations to the different part-task demands.

Second, receiving part-task congruent representational tools induced teams of learners to exhibit more communicative activities (i.e., focusing, checking and argumentation) than teams of learners receiving representational tools that were partly or not congruent for the part-task demands. Since carrying out such activities is regarded as a prerequisite for establishing and maintaining a shared understanding of the domain and to argue about it, this might have fostered learning (Clark \& Brennan, 1991; Erkens \& Janssen, 2008). This result is consistent with studies on CSCL indicating that the computer tools provided by the environment must enable learners to easily refer to and relate their contributions to those of others (Mühlpfordt \& Stahl, 2007; Suthers et al., 2003).

In sum, the obtained results are in line with those of others who stress the importance of sequencing and interrelating multiple (i.e., qualitative and quantitative) representations of the knowledge domain during the (collaborative) performance of a complex learningtask (Frederiksen \& White, 2002; Jonassen, 2003; Ploetzner et al., 1999).These results also might have several implications for designing learning-environments (e.g., CSCL-environments) aimed at fostering complex learning. Combining the advantages of scripting and using multiple presentational tools facilitates learners in constructing and discussing different representations of the domain. When properly matched to the part-task demands, the complementary function of those representations can evoke elaborated and meaningful discussion of the domain and foster complex learning-task performance (Ainsworth, 2006; Slof et al., 2010).

\section{Limitations and suggestions for future research}

Although the results seem promising, there are multiple reasons to assume that the design principles behind the representational scripting do not automatically apply to other domains, learning tasks, and settings. To address this, several remarks and suggestions for future research are provided.

The conducted study took place in the field of business-economics. Although many domains (e.g., meteorology, physics, urban planning, and science) require multiple problem representations, the effects of a particular design depend on the characteristics of the learning task and the involved knowledge domains (Kirschner et al., 2004; Veldhuis-Diermanse, 2002). When designing tools and/or learning environments, one should take this carefully into account. The effect of the design of the representational scripting does not automatically apply to all complex learning tasks and knowledge domains. To address this, educators and instructional designers should gain insight into the specifics of the learning tasks by conducting a learning-task analysis (Anderson \& Krathwohl, 2001). If analysis reveals that the entire task needs to be sequenced in part-tasks, their required domain-specific perspectives need to be determined. Based on these insights, the sequence and the demands of the part-tasks can be specified and part-task congruent (representational) tools can be developed.

All learners gained more domain knowledge indicating that collaboratively constructing, adjusting and discussing qualitative and/ or quantitative representations might foster individual learning. However, whereas teams receiving part-task congruent tools performed better on the complex learning-task, they, on average, did not score significantly higher on the post-knowledge test. There seem to be, at least, three explanations that might account for this.

First, the study reported on here was integrated into the curriculum of participating schools and both post-test scores as well as the complex learning-task performance affected the GPA. When tailoring the measurement of the learning gains to the specifics of the curriculum there were no suitable standardized measurement instruments available. These instruments, therefore, had to be developed in cooperation with the teachers, which made them more ecologically valid for measuring individual and team learning gains. Although this is how teachers usually work with and assess their learners, this approach might have compromised the internal consistency of the knowledge tests used. That is, several items were deleted from the pre-knowledge test and the post-knowledge test to, eventually, reach low but at least acceptable internal reliability scores (i.e., Cronbach's alpha's). Reducing the number of items in the knowledge tests might have restricted learners receiving part-task congruent representational tools in fully demonstrating gained declarative domain-knowledge. Using less restrictive internal consistency tests (e.g., Kuder-Richardson test; see Kuder \& Richardson, 1937) when administering classroom developed knowledge tests (Rudner \& Schafer, 2002) would address this. Those tests, however, are only suited for knowledge tests consisting of dichotomous items (i.e., " 0 " for an incorrect answer and "1" for a correct answer). Since participants were students from six business-economics classes in three secondary schools, the more restricted test (i.e., Cronbach alpha) was used in this study.

Second, research on CSCL indicates that individual learners do not always (equally) learn from participating in teams (Fischer et al., 2002). What individual learners or teams of learners gain from their collaboration strongly depends on the quality of the collaboration process (Barron, 2003; Ding, 2009; Van Boxtel, 2004). Although coding and counting the number of exhibited communicative activities might give some indication of the quality of collaboration (Erkens \& Janssen, 2008), it, however, does not lead to fully understanding the dynamics of collaborative learning (Hmelo-Silver, Chernobilsky, \& Jordan, 2008). For example, it does not provide insight into (1) the evolution of understanding and the correctness of the domain-specific discussions and (2) how learners translate information from and coordinate information between their constructed visualizations. One approach to address this in problembased learning is to determine how many errors (specific) learners make in their discussion when interrelating the concepts to each other per problem phase. Insight into the quality can be gained by comparing the number and kinds of errors learners make in each phase. Another approach might be to focus more on the quality of the knowledge-construction process, for example, by analyzing whether and how learners elaborate on previous ideas and statements (Schellens \& Valcke, 2005).

Finally, the lack of differences in individual learning gains between conditions might be accounted for by how the effects of complex learning were measured. That is, knowledge tests often only measure recall and simple comprehension of the subject matter. The knowledge tests used in this study are a case in point here in that they did not enable learners to demonstrate whether they were better able to apply their understanding of the domain, which also can be regarded as a form of learning gains. It might, thus, be the case that the knowledge tests used were not sensitive enough to gain insight into the possible learning gains in terms of complex learning (Bigelow, 2004; Loyens \& Gijbels, 2008). Examining the effects of complex learning in based on acquired declarative knowledge of the domain could, thus, be questioned. Future research might, therefore, take an interest in measuring deep understanding of the domain content, collaboration skills, problem-solving skills and the ability to apply the acquired knowledge and skills in other situations (i.e., transfer). More concretely, instead of administering 
knowledge tests aimed at measuring learners' recall (i.e., reproduction) of concepts, principles and procedures, new assessment forms measuring learners application (i.e., production) of the content of the domain should be developed. For example, another but related problem task might be used to measure whether individual learners or teams of learners gained more skills to apply their domain knowledge or problem-solving skills. Again, the quality of the decisions and solutions could be evaluated and insight into the learning process could be measured by either observing or using stimulated recall interviews afterwards.

\section{References}

Ainsworth, S. (2006). DeFT: A conceptual framework for considering learning with multiple representations. Learning and Instruction, 16, 183-198.

Anderson, L. W., \& Krathwohl, D. R. (2001). A taxonomy for learning, teaching, and assessing: A revision of Bloom's taxonomy of educational objectives. New York: Longman.

Barron, B. (2003). When smart groups fail. Journal of the Learning Sciences, 12, $307-359$

Bera, S., \& Liu, M. (2006). Cognitive tools, individual differences, and group processing as mediating factors in a hypermedia environment. Computers in Human Behavior, 22, 295-319.

Bigelow, J. D. (2004). Using problem-based learning to develop skills in solving unstructured problems. Journal of Management Education, 28, 591-609.

Bodemer, D., \& Faust, U. (2006). External and mental referencing of multiple representations. Computers in Human Behavior, 22, 27-42.

Clark, H. H., \& Brennan, S. E. (1991). Grounding in communication. In L. B. Resnick, J M. M. Levine, \& S. D. Teasley (Eds.), Perspectives on socially shared cognition (pp. 127-149). Washington, DC: American Psychological Association.

De Simone, C., Schmid, R. F., \& McEwan, L. A. (2001). Supporting the learning process with collaborative concept mapping using computer-based communication tools and processes. Educational Research and Evaluation, 7, 263-283.

Dennen, V. P. (2008). Looking for evidence of learning: Assessment and analysis methods for online discourse. Computers in Human Behavior, 24, 205-219.

Dillenbourg, P. (2002). Over-scripting CSCL: The risks of blending collaborative learning with instructional design. In P. A. Kirschner (Ed.), Three worlds of CSCL: Can we support CSCL? (pp 61-91). Heerlen, The Netherlands: Open Universitei Nederland.

Ding, N. (2009). Content analysis: Visualizing the sequential process of knowledge elaboration in computer-supported collaborative problem-solving. Computers and Education, 52, 509-519.

Elen, J., \& Clarebout, G. (2007). Supporting learning: Increasing complexity? Computers in Human Behavior, 23, 1162-1166.

Erkens, G. (2005). Multiple Episode Protocol Analysis (MEPA). Version 4.10. The Netherlands: Utrecht University.

Erkens, G., \& Janssen, J. (2008). Automatic coding of online collaboration protocols. International Journal of Computer-Supported Collaborative Learning, 3, 447-470.

Fischer, F., Bruhn, J., Gräsel, C., \& Mandl, H. (2002). Fostering collaborative knowledge construction with visualization tools. Learning and Instruction, 12 213-232.

Frederiksen, J. R., \& White, B. Y. (2002). Conceptualizing and constructing linked models: Creating coherence in complex knowledge systems. In P. Brna, M. Baker, K. Stenning, \& A. Tiberghein (Eds.), In the role of communication in learning to model (pp. 69-96). Mahwah, NJ: Lawrence Erlbaum Associates Publishers.

Greene, T. R. (1989). Children's understanding of class inclusion hierarchies: The relation between external representation and task performance. Journal of Experimental Child Psychology, 48, 62-69.

Hilbert, T. S., \& Renkl, A. (2008). Concept mapping as a follow-up strategy to learning form texts: What characterizes good and poor mappers? Instructional Science, 36, 53-73.

Hmelo-Silver, C. E., Chernobilsky, E., \& Jordan, R. (2008). Understanding collaborative learning processes in new learning environments. Instructional Science, 36, 409-430.

Hmelo-Silver, C. E., Duncan, R. G., \& Chinn, C. A. (2007). Scaffolding and achievement in problem-based and inquiry learning: A response to Kirschner, Sweller, and Clark (2006). Educational Psychologist, 42, 99-107.

Jaspers, J. G. M., Broeken, M., \& Erkens, G. (2005). Virtual Collaborative Research Institute (VCRI). Version 2.2. Utrecht, The Netherlands: Utrecht University.

Jeong, A., \& Joung, S. (2007). Scaffolding collaborative argumentation in asynchronous discussions with message constraints and message labels. Computers and Education, 48, 427-445.

Johnson, D. W., \& Johnson, R. T. (2009). An educational psychology success story: Social interdependency theory and cooperative learning. Educational Researcher, 38, 365-379.

Jonassen, D. H. (2003). Using cognitive tools to represent problems. Journal of Research on Technology in Education, 35, 362-381.

Jonassen, D. H., \& Ionas, I. G. (2008). Designing effective support for causal reasoning. Educational Technology Research and Development, 56, 287-308.

Kenny, D. A., Kashy, D. A., \& Cook, W. L. (2006). Dyadic data analysis. New York/ London: The Guilford Press.
Kirschner, P. A., Martens, R. L., \& Strijbos, J.-W. (2004). CSCL in higher education? A framework for designing multiple collaborative environments. In J.-W. Strijbos, P. A. Kirschner, \& R. L. Martens (Eds.), What we know about CSCL, and implementing it in higher education (pp. 3-30). Boston: Kluwer Academic Publishers.

Kirschner, F. C., Paas, F., \& Kirschner, P. A. (2009). Individual and group-based learning from complex cognitive tasks: Effects on retention and transfer efficiency. Computers in Human Behavior, 25, 306-314.

Kollar, I., Fischer, F., \& Slotta, J. D. (2007). Internal and external scripts in computersupported collaborative inquiry learning. Learning and Instruction, 17, 708-721.

Kollöffel, B., Eysink, T. H. S., \& De Jong, T. (2010). The influence of learner-generated domain representations on learning combinatorics and probability theory. Computers in Human Behavior, 23, 1-11.

Kozma, R. (2003). The material features of multiple representations and their cognitive and social affordances for science understanding. Learning and Instruction, 13, 205-226.

Kuder, G. F., \& Richardson, M. W. (1937). The theory of the estimation of test reliability. Psychometrika, 2, 151-160.

Lazakidou, G., \& Retalis, S. (2010). Using computer supported collaborative learning strategies for helping students acquire self-regulated problem-solving skills in mathematics. Computers and Education, 54, 3-13.

Lee, Y., \& Nelson, D. W. (2005). Viewing or visualizing - Which concept map strategy works best on problem-solving performance? British Journal of Educational Technology, 36, 193-203.

Leutner, D., Leopold, C., \& Sumfleth, E. (2009). Cognitive load and science text comprehension: Effect of drawing and mentally imagining text content. Computers in Human Behavior, 25, 284-289.

Löhner, S., Van Joolingen, W. R., \& Savelsbergh, E. R. (2003). The effect of external representations on constructing computer models of complex phenomena. Instructional Science, 31, 395-418.

Loyens, S. M. M., \& Gijbels, D. (2008). Understanding the effects of constructivist learning environments: Introducing a multi-directional approach. Instructional Science, 36, 351-357.

Mercer, N., Littleton, K., \& Wegerif, R. (2004). Methods for studying the processes of interaction and collaborative activity in computer-based educational activities. Technology, Pedagogy and Education, 13, 195-212.

Mühlpfordt, M., \& Stahl, G. (2007). The integration of synchronous communication across dual interaction spaces. In C. A. Chinn, G. Erkens, \& S. Puntambekar (Eds.), Proceedings of the 8th international conference on computer supported collaborative learning (pp. 522-531). New Brunswick, NJ: International Society of the Learning Sciences.

Nesbit, J. C., \& Adesope, O. O. (2006). Learning with concept and knowledge maps: A meta-analysis. Review of Educational Research, 76(3), 413-448.

Ploetzner, R., Fehse, E., Kneser, C., \& Spada, H. (1999). Learning to relate qualitative and quantitative problem representations in a model-based setting for collaborative problem solving. Journal of the Learning Sciences, 8, 177-214.

Rudner, L., \& Schafer, W. (2002). What teachers need to know about assessment. Washington, DC: National Education Association.

Schellens, T., \& Valcke, M. (2005). Collaborative learning in asynchronous discussion groups: What about the impact on cognitive processing? Computers in Human Behavior, 21, 957-975.

Schiffrin, D. (1987). Discourse markers. Cambridge, MA: Cambridge University Press.

Schnotz, W., \& Kürschner, C. (2008). External and internal representations in the acquisition and use of knowledge: Visualization effects on mental model construction. Instructional Science, 36, 175-190.

Sharples, M. (2010). The design of personal mobile technologies for lifelong learning. Computers and Education, 34, 177-193.

Slof, B., Erkens, G., Kirschner, P. A., Jaspers, J. G. M., \& Janssen, J. (2010). Guiding students' online complex learning-task behavior through representational scripting. Computers in Human Behavior, 26, 927-939.

Spector, J. M. (2008). Cognition and learning in the digital age: Promising research and practice. Computers in Human Behavior, 24, 249-262.

Stull, A. T., \& Mayer, R. E. (2007). Learning by doing versus learning by viewing: Three experimental comparisons of learner-generated versus author-provided graphic organizers. Journal of Educational Psychology, 99, 808-820.

Suthers, D. D. (2006). Technology affordances for intersubjective meaning making: A research agenda for CSCL. International Journal of Computer-Supported Collaborative Learning, 1, 315-337.

Suthers, D. D., Girardeau, L. E., \& Hundhausen, C. D. (2003). Comparing the roles of representations in face-to-face and online computer supported collaborative learning. Computers and Education, 41, 335-351.

Van Amelsvoort, M., Andriessen, J., \& Kanselaar, G. (2007). Representational tools in computer-supported collaborative argumentation-based learning: How dyads work with constructed and inspected argumentative diagrams. Journal of the Learning Science, 16, 485-521.

Van Boxtel, C. A. M. (2004). Studying peer interaction from three perspectives: The example of collaborative concept learning. In J. L. van der Linden \& P. Renshaw (Eds.), Dialogic learning: Shifting perspectives to learning, instruction and teaching (pp. 125-144). Dordrecht, The Netherlands: Kluwer Academic Publishers.

Van Bruggen, J. M., Boshuizen, H. P. A., \& Kirschner, P. A. (2003). A cognitive framework for cooperative problem solving with argument visualization. In $P$. A. Kirschner, S. J. Buckingham Shum, \& C. S. Carr (Eds.), Visualizing argumentation: Software tools for collaborative and educational sense-making (pp. 25-47). London: Springer. 
Van Merriënboer, J. J. G., \& Kirschner, P. A. (2007). Ten steps to complex learning. A systematic approach to four-component instructional design. Mahwah, NJ: Lawrence Erlbaum Associates Publishers.

Van Meter, P., \& Garner, J. (2005). The promise and practice of learner-generated drawing: Literature review and synthesis. Educational Psychology Review, 17, 285-325.

Vekiri, I. (2002). What is the value of graphical displays in learning? Educational Psychology Review, 14, 261-312.
Veldhuis-Diermanse, A. E. (2002). CSCLearning? Participation, learning activities and knowledge construction in computer-supported collaborative learning in higher education. Unpublished Ph.D. thesis. The Netherlands: Wageningen University. Zydney, J. M. (2010). The effect of multiple scaffolding tools on students' understanding, consideration of different representations, and misconceptions of a complex problem. Computers and Education, 54, 360-370. 